\title{
DISTRIBUIÇÃO LONGITUDINAL DE SEMENTES DE ALGODÃO E GIRASSOL COM DIFERENTES VELOCIDADES E INCLINAÇÕES EM DOSADORES PNEUMÁTICOS
}

\section{LONGITUDINAL DISTRIBUTION OF COTTON AND SUNFLOWER SEEDS WITH DIFFERENT SPEEDS AND INCLINATION IN PNEUMATIC METER}

\author{
Airton dos Santos ALONÇO ${ }^{1}$ \\ Hendrigo. A. T. DA SILVEIRA ${ }^{2}$ \\ Kátia Maria CARDINAL ${ }^{3}$ \\ Giovana Peres RIST ${ }^{4}$
}

\section{RESUMO}

O trabalho foi conduzido no Laboratório de Pesquisa e Desenvolvimento de Máquinas Agrícolas - LASERG, localizado na Universidade Federal de Santa Maria, com o auxílio de uma bancada que reproduz, artificialmente, as condições operacionais sob as quais a máquina efetua a semeadura no campo. Utilizou-se o delineamento experimental blocos casualizados com parcelas sub-subdivididas, com três fatores experimentais: inclinação transversal do dosador com três níveis $\left( \pm 11^{\circ}\right.$ e nivelado), velocidade de deslocamento com três níveis $\left(5 ; 7,5\right.$ e $\left.10 \mathrm{~km} \mathrm{~h}^{-1}\right)$ e três dosadores de sementes pneumáticos. As sementes utilizadas foram girassol e algodão, realizou-se a medição de 250 espaçamentos entre sementes, medidos com o auxílio de uma trena de $30 \mathrm{~m}$, esticada sobre a esteira. Para a regularidade de distribuição avaliou-se o nível de espaçamentos aceitáveis, duplos e falhos e pelo coeficiente de variação dos dados coletados na esteira de sementes. Os dados foram submetidos à análise de variância (ANOVA). Os resultados obtidos mostram que o aumento da velocidade de semeadura influiu significativamente nos resultados médios de espaçamentos aceitáveis e falhos, além da precisão. Para o fator inclinação não houve diferença significativa pelo teste de $F$.

Palavras chave: Inclinação, Dosadores, Velocidade, Algodão, Girassol.

\section{ABSTRACT}

This study was conducted at the Laboratory of Research and Development of Agricultural Machinery (LASERG), located in the Universidad Federal de Santa Maria, with the aid of a bench that reproduces artificially, the conditions under which the machine performs in sowing field. The experimental design was randomized blocks of type with split split-plot with three experimental factors: cross slope of the three dosing levels $\left( \pm 11^{\circ}\right.$ and level), travel speed with three levels $(5,7.5$ and $10 \mathrm{~km} \mathrm{~h} \mathrm{-1)} \mathrm{and} \mathrm{three} \mathrm{pneumatic} \mathrm{dispensing} \mathrm{seeds.} \mathrm{The} \mathrm{seeds} \mathrm{used} \mathrm{were} \mathrm{sunflower} \mathrm{and} \mathrm{cotton,} \mathrm{the} \mathrm{measurement} \mathrm{was} \mathrm{made}$ 250 seed spacings measured with the aid of a tape of $30 \mathrm{~m}$, stretched on the mat. The regularity of distribution was assessed by the level of acceptable spacing, double and flawed and the coefficient of variation of the data collected in the wake of seeds. Data were subjected to analysis of variance (ANOVA). The results show that increasing the seeding rate significantly affected the average results of acceptable spacing and flawed, and accuracy. For the slope factor no significant difference by F test.

Keywords: tilt, dispensers, speed, cotton, sunflower

\footnotetext{
${ }^{1}$ Engenheiro Agrícola, Professor Dr. Associado, Departamento de Engenharia Rural, Universidade Federal de Santa Maria, Avenida Roraima, número, 1000, Cidade Universitária, Bairro Camobi, Santa Maria, RS, Brasil, 97105-900 (airtonalonço@gmail.com)

${ }^{2}$ Engenheiro Agrícola, Mestrando, Programa de Pós-graduação em Engenharia Agrícola, Universidade Federal de Santa Maria, Santa Maria, $\mathrm{RS}$, Brasil "in memoriam".

${ }^{3}$ Estudante de Zootecnia, Universidade Federal de Santa Maria, Santa Maria, RS, Brasil, katia.zootecnia@hotmail.com.

${ }^{4}$ Estudante de Zootecnia, Universidade Federal de Santa Maria, Santa Maria, RS, Brasil, giovannarist@yahoo.com.br
} 
ALONÇO, A. dos S. et al. Distribuição longitudinal de sementes...

\section{INTRODUÇÃO}

Atualmente o Brasil é tido como o país com maior potencial agrícola do mundo, o que lhe coloca no compromisso de aumentar a eficiência nas operações agrícolas, transformando isso em maior produtividade. A semeadura é uma das mais importantes práticas culturais associada à produtividade das culturas, deste modo, torna-se de fundamental importância que esta operação seja realizada com o maior grau de qualidade e precisão possível.

A semeadora é definida por Machado et al. (2005), como sendo a máquina agrícola que tem a função de colocar no solo os mais variados tipos de sementes, sem danos mecânicos, dentro de densidade e com espaçamento e profundidade recomendados para o pleno desenvolvimento da cultura. Para Balastreire (1987), vários fatores afetam a operação de semeadura, podendo estes estar relacionados à semente, ao solo, à máquina, ao clima $\mathrm{e}$ ao operador. Para que a semeadora atenda ao objetivo desejado, é necessário que todos os mecanismos da máquina executem perfeitamente suas funções e estejam regulados adequadamente para a cultura desejada.

Os componentes principais de uma semeadora são divididos por Delafosse (1986) em: dosadores de insumos, tubos condutores, reservatórios, chassi, órgãos de engate, sulcadores, cobridores, compactadores e mecanismos de acionamento, ou classificados de acordo com Murray et al. (2006), em componentes de ataque inicial ao solo; componentes de abertura do sulco e controle de profundidade; componentes de dosagem de sementes e componentes de condução das sementes.

O mecanismo dosador é responsável por conduzir as sementes do reservatório, uma a uma ou em grupos, segundo densidade de semeadura preestabelecida ABNT (1994), sem danificá-las e de acordo com os padrões recomendados para cada tipo de cultura. Para a semeadura de algodão e girassol são utilizados, em sua maioria, dosadores mecânicos de disco horizontal e dosadores pneumáticos a vácuo.

A avaliação do desempenho de mecanismos dosadores de sementes pneumáticos, em nível laboratorial, leva em consideração a velocidade de deslocamento da semeadora, simulada em bancada de ensaios pela mudança da rotação do disco dosador, as regulagens básicas do mecanismo dosador e as posições do mesmo em relação ao solo (Kurachi et al., 1989).

A uniformidade de distribuição de sementes é influenciada por fatores como mecanismos dosadores e condutores. Cada mecanismo de dosagem possui características particulares, como por exemplo, velocidade periférica, tamanho e formato dos orifícios e nível de sementes no reservatório, (dosador mecânico) e velocidade periférica e pressão de trabalho (dosador pneumático).

A inclinação de trabalho é uma importante característica verificada na atividade de semeadura no campo, afetando diretamente o comportamento dos dosadores. A inclinação pode ser simulada em laboratório através de bancada de ensaios.

De acordo com Silva et al. (2000) e Kurachi et al. (1989), a velocidade periférica dos discos dosadores está diretamente relacionada com a velocidade de deslocamento da máquina semeadora. A velocidade ideal de semeadura é aquela em que o sulco é aberto e fechado sem remover exageradamente o solo, permitindo distribuir as sementes com espaçamentos e profundidades constantes (Vieira et al., 2002). O aumento da velocidade da semeadora influi na redução do estande e, consequentemente, do rendimento das culturas (Furlani et al., 1999).

Sendo de fundamental importância a uniformidade de distribuição de sementes e a regulagem das máquinas, este trabalho buscou realizar ensaios em uma bancada laboratorial a fim de estabelecer melhores condições de operação de dosadores para as culturas de girassol e algodão.

\section{MATERIAL E MÉTODOS}

Os ensaios foram realizados no Laboratório de Pesquisa e Desenvolvimento de Máquinas Agrícolas (LASERG), da Universidade Federal de Santa Maria posicionada geograficamente na Depressão Central do Estado do Rio Grande do Sul/Brasil, cujo centro geográfico corresponde às seguintes coordenadas: Latitude Sul $29^{\circ} 72^{\prime} 05^{\prime \prime}$ e Longitude Oeste $53^{\circ} 70^{\prime} 32^{\prime \prime}$ (exatamente no centro do prédio do LASERG) e altitude média de $99 \mathrm{~m}$ (Santa Maria/RS). Os ensaios em laboratórios reproduzem, artificialmente, as condições operacionais sob as quais a máquina efetua a semeadura no campo, para tal foi necessário projetar e desenvolver uma bancada de testes.

O projeto da bancada de ensaio de dosadores de sementes está descrito em Silveira et al (2010) e Alonço et al. (2010), e foi baseado em metodologias de projeto de máquinas agrícolas e de produtos, como a descrita em Romano (2003).

Quanto à estrutura da bancada, esta apresenta na parte superior, trilhos que possibilitam a fixação dos diferentes mecanismos dosadores. A inclinação transversal e longitudinal de trabalho dos dosadores é simulada, através de pontos compostos por rótulas e modificadas com o curso de parafusos. A ligação do movimento rotacional transmitido do motor é realizada com o auxílio de um eixo cardan, com juntas universais, pois cada dosador possui uma característica dimensional própria.

O controle e o comando da rotação do disco dosador de sementes são realizados com o auxílio de um inversor de frequência CFW-08. O motor elétrico trifásico de indução assíncrono possui potência de $736 \mathrm{~W}$ e rotação de $1720 \mathrm{rpm}$. O motor está acoplado a um par de polias, unido por correia (motora $-70 \mathrm{~mm}$ e movida $-120 \mathrm{~mm}$ ), um redutor de engrenagem e eixo sem fim com relação de transmissão de $1: 11$, totalizando uma redução de 19,64 vezes a rotação do motor. A amplitude de variação de rotação do disco está na faixa de zero a $91 \mathrm{rpm}$. 
ALONÇO, A. dos S. et al. Distribuição longitudinal de sementes...

Os dosadores de sementes utilizados no trabalho são comercialmente utilizados em semeadoras disponíveis no mercado brasileiro e internacional, constituídos por um disco dosador vertical, com principio de coleta das sementes a vácuo (pressão negativa), disponíveis para uso no Laboratório. São acionados pelo cardam da bancada com um acoplamento simples, fixados na estrutura da bancada por parafusos. As regulagens disponíveis nos mecanismos dosadores não foram fatores de estudo, ficando estabelecida a regulagem recomendada pelos fabricantes para cada tipo de semente.

A Tabela 1 especifica algumas características dimensionais dos três dosadores estudados,

TABELA 1 - Principais características dos dosadores avaliados nos ensaios.

\begin{tabular}{|c|c|c|}
\hline \multirow{2}{*}{ Parâmetros } & \multicolumn{2}{|l|}{ Dosador Verde } \\
\hline & Girassol & Algodão \\
\hline Pressão de trabalho (kPa) & $-1,49$ & $-1,99$ \\
\hline Diâmetro do disco $(m)^{*}$ & 0,220 & 0,215 \\
\hline Número de orifícios do disco & 30 & 64 \\
\hline Número de fileiras & 1 & 2 \\
\hline \multirow[t]{2}{*}{ Diâmetro do orifício (mm) } & 2,60 & 3,50 \\
\hline & \multicolumn{2}{|l|}{ Dosador Cinza } \\
\hline Pressão de trabalho $(\mathrm{kPa})$ & $-3,5 a-5,5$ & $-3,5 a-5,5$ \\
\hline Diâmetro do disco $(\mathrm{m})^{*}$ & 0,215 & 0,215 \\
\hline Número de orifícios do disco & 24 & 75 \\
\hline Número de fileiras & 1 & 1 \\
\hline \multirow[t]{2}{*}{ Diâmetro do orifício (mm) } & 3,0 & 4,5 \\
\hline & \multicolumn{2}{|l|}{ Dosador Amarelo } \\
\hline Pressão de trabalho (kPa) & $-5,0$ & $-5,0$ \\
\hline Diâmetro do disco $(\mathrm{m})^{*}$ & 0,20 & 0,20 \\
\hline Número de orifícios do disco & 24 & 72 \\
\hline Número de fileiras & 1 & 1 \\
\hline Diâmetro do orifício (mm) & 3,0 & 3,5 \\
\hline
\end{tabular}

*diâmetro médio das fileiras de captação das sementes.

Para contagem de espaçamentos entre sementes foi projetada uma esteira de borracha com $17,5 \mathrm{~m}$ de comprimento e $0,15 \mathrm{~m}$ de largura, que simula a velocidade de deslocamento de semeadora, esta esteira é revestida com feltro de forração, com $0,003 \mathrm{~m}$ de espessura, mesmo material utilizado por Jasper et al. (2009).A estrutura de sustentação da esteira possui formato de "V" onde ocorre a descarga das sementes pelo tubo condutor, simulando o sulco de semeadura e evitando o deslocamento das sementes até o fim da esteira. Seu acionamento é realizado por um motor elétrico trifásico de indução assíncrono de 2208 W acionado por um inversor de frequência CFW-10.

A bancada geradora de vácuo foi projetada com a finalidade de exercer pressão negativa para captação das sementes pelo disco dosador. O acionamento deste e realizado por motor elétrico de indução trifásico de $3677,5 \mathrm{~W}$ de potência, rotação de $3510 \mathrm{rpm}$, proporcionando a rotação original através de polias e correia, de 5400 rpm no eixo da turbina. Foi incorporado um sistema de controle da pressão negativa através de uma válvula de alívio de pressão, monitorado por um vacuômetro. O controle das rotações do motor elétrico foi realizado com um tacômetro digital com precisão de $\pm 0,05 \%+1 \mathrm{rpm}$, onde para cada rotação do motor, foi aferida uma rotação correspondente no inversor.

O tubo condutor de sementes foi mantido o mesmo para todos os dosadores ensaiados, com comprimento de $345 \mathrm{~mm}$ com abertura superior de $55 \times 37 \mathrm{~mm}$ e inferior com $35 \times 15 \mathrm{~mm}$ com inclinações de $8^{\circ}$ e $17^{\circ}$, sendo que a inclinação transversal do tubo seguia o mesmo parâmetro dos dosadores. 
ALONÇO, A. dos S. et al. Distribuição longitudinal de sementes...

Em relação aos dosadores, foram aferidas algumas características como pressão de trabalho, diâmetro do disco, número de orifícios do disco, número de fileiras e diâmetro do orifício.

Para realização dos ensaios foram utilizadas sementes de algodão e girassol, com procedência comercial. Para maior detalhamento das características das sementes foram medidas amostras de 100 sementes, com o auxílio do paquímetro, a fim de estabelecer as médias da largura, espessura, comprimento e o desvio padrão dos dados. As sementes foram utilizadas somente uma vez, sendo descartadas posteriormente, os reservatórios de sementes foram preenchidos no início de cada ensaio.

As velocidades e as inclinações transversais estudadas, foram determinadas a partir da norma ISO 7256/1. Com isso foram determinadas as velocidades de $5 \mathrm{~km} \mathrm{~h}^{-1}$ mesma utilizada por Santos et al. (2008), $7,5 \mathrm{~km} \mathrm{~h}^{-1}$ por ser uma intermediária e 10 $\mathrm{km} \mathrm{h}^{-1}$, máxima recomendada pelos fabricantes, sem ocasionarem falhas de distribuição de sementes, e as inclinações determinadas em $11^{\circ}$ para a esquerda e para direita, assim como nivelada ao sentido do deslocamento.

O delineamento experimental utilizado foi do tipo blocos casualizados com parcelas subsubdivididas, com três fatores experimentais: inclinação transversal do dosador com três níveis, velocidade de deslocamento com três níveis e três dosadores de sementes pneumáticos, resultando em um fatorial $3 \times 3 \times 3$, com três repetições para cada tratamento, totalizando 81 unidades básicas para cada tipo de semente. Os tratamentos foram formados pela combinação da inclinação transversal, com o dosador e as velocidades de semeadura simuladas na bancada de ensaio. Esta sequência foi utilizada para todas as sementes, sendo modificada apenas a casualização dos tratamentos dentro de cada bloco, ou seja, a ordem de execução do experimento foi sorteada com auxílio de papéis numerados.

Em cada unidade básica foi realizada a medição de 250 espaçamentos entre sementes, medidos com o auxílio de uma trena. A regularidade de distribuição de sementes foi determinada conforme a ISO 7256/1 e ABNT (1994), sendo avaliada pelo nível de espaçamentos aceitáveis, duplos e falhos e pelo coeficiente de variação. Os dados de espaçamentos coletados foram submetidos à análise de variância (ANOVA), e quando encontradas diferenças significativas pelo teste $F$, as médias foram comparadas pelos testes de Tukey ao nível de $5 \%$ de probabilidade de erro.

\section{RESULTADOS E DISCUSSÃO}

O diâmetro do disco utilizado quando este possui duas ou mais carreiras, foi determinado conforme descrito por Teixeira et al. (2009), como sendo o diâmetro médio das carreiras de orifícios dosadores. A velocidade periférica dos discos dos três dosadores não excedeu a referência citada (FAO apud Delafosse (1986) $0,29 \mathrm{~m} \mathrm{~s}^{-1}$ ). A densidade de sementes de algodão estabelecida de acordo com a população de $100.000,00$ sementes ha $^{-1}$, resultando em 9 sem $\mathrm{m}^{-1}$.

Para o Teste $F$ não houve diferença estatística no fator Inclinações (F1) para nenhuma das variáveis estudadas. Já para o fator Dosadores (F2) houve diferença estatística a $1 \%$ de probabilidade de erro para todas as variáveis estudadas, exceto para a precisão (Tabela 2). Quando analisado o fator Velocidade (F3), todos as variáveis obtiveram diferença estatística a $1 \%$ de erro. Nas interações foi verificado uma diferença em relação ao girassol, não houve interação entre os fatores $\mathrm{F} 1 \mathrm{xF} 2$ e F1x$F 2 x F 3$, somente havendo diferença estatística nas interações F1xF3 para as variáveis espaçamentos aceitáveis e falhos e na interação F2xF3 para a variável sementes por metro.

Para as sementes de algodão, a diferença porcentual média entre o valor dimensionado e o valor de densidade real de sementes, foi de $4,1 \%$, a média geral dos ensaios foi de $8,92 \mathrm{sem} \mathrm{m}^{-1}$. Valores estes concordam com os limites propostos por Siqueira e Casão Junior (2002) que citam valores \pm $10 \%$ de desvios da dosagem dimensionada para a semeadura, exceto a velocidade de $5 \mathrm{~km} \mathrm{~h}^{-1}$ do dosador verde, que apresentou $10,3 \%$ e $10,4 \%$, acima do estabelecido, para a inclinação direita e esquerda, respectivamente.

O dosador cinza apresentou melhores resultados de densidade de sementes, em média ficando $1,2 \%$ abaixo da densidade recomendada, não diferindo significativamente do dosador amarelo, que também não alcançou o limite pré-estabelecido, diferentemente do dosador verde que dosou, em média, 3,67 \% a mais. Os valores de precisão não ultrapassam os limites propostos por Kachman e Smith (1995), indicando uma mudança significativa de precisão com o aumento de velocidade, sendo o melhor nível obtido na velocidade de $5 \mathrm{~km} \mathrm{~h}^{-1}$, seguido de $7,5 \mathrm{~km} \mathrm{~h}^{-1}$ e os piores resultados encontrados na maior velocidade de trabalho $\left(10 \mathrm{~km} \mathrm{~h}^{-1}\right)$.

Para os espaçamentos múltiplos, o dosador amarelo obteve média de $16,46 \%$, não diferindo do dosador cinza, com $17,90 \%$. O dosador verde apresentou 24,06 \% diferenciando-se dos outros dois. Os resultados de espaçamentos múltiplos aumentam com o aumento da velocidade, resultados que concordam com resultados obtidos por Fey et al. (2000), Silva et al. (2000) e Mahl et al. (2004) citando que a elevação da velocidade de semeadura reduz a qualidade de distribuição de sementes.

As médias de espaçamentos aceitáveis verificadas na Tabela 2, evidenciam a interação significativa entre a inclinação transversal e velocidade de semeadura, além de descrever a influência significativa do fator dosador. O dosador cinza apresentou $64,99 \%$ de aceitáveis, não diferindo do dosador amarelo com $64,61 \%$, como sendo os dois que obtiveram melhores resultados. O aumento da velocidade de semeadura influi negativamente no índice de espaçamentos aceitáveis, sendo o melhor resultado obtido na menor velocidade, o que condiz com os encontrados por Fey et al. (2000), Tesouro et al. (2000) e Garcia et al. (2006). 
ALONÇO, A. dos S. et al. Distribuição longitudinal de sementes...

TABELA 2 - Resultados médios da análise de variância e do teste de médias para densidade de sementes, precisão e espaçamentos entre sementes de algodão.

\begin{tabular}{|c|c|c|c|c|c|}
\hline \multirow[b]{2}{*}{ Fatores } & \multicolumn{5}{|c|}{ Variáveis } \\
\hline & Sem $\mathrm{m}^{-1}$ & Precisão (\%) & Múltiplos (\%) & Aceitáveis (\%) & Falhos (\%) \\
\hline \multicolumn{6}{|l|}{ Inclinação (F1) } \\
\hline$-11^{\circ}$ & 8,96 & 26,21 & 18,72 & 64,04 & 17,23 \\
\hline nivelado & 8,83 & 25,38 & 18,92 & 64,21 & 16,87 \\
\hline $11^{\circ}$ & 8,99 & 25,92 & 20,77 & 60,53 & 18,70 \\
\hline \multicolumn{6}{|l|}{ Dosador (F2) } \\
\hline Amarelo & $8,55 a$ & 25,48 & $16,46 \mathrm{a}$ & $64,61 \mathrm{a}$ & $18,93 \mathrm{~b}$ \\
\hline Verde & $9,33 \mathrm{~b}$ & 26,15 & $24,06 \mathrm{~b}$ & $59,18 b$ & $16,75 a$ \\
\hline Cinza & $8,89 a$ & 25,88 & $17,90 \mathrm{a}$ & $64,99 a$ & $17,11 \mathrm{a} \mathrm{b}$ \\
\hline \multicolumn{6}{|l|}{ Velocidade (F3) } \\
\hline 5,0 & $9,22 \mathrm{~b}$ & $24,95 a$ & $18,43 a$ & $67,24 a$ & $14,32 \mathrm{a}$ \\
\hline 7,5 & 8,78 a & $25,71 b$ & $18,69 a$ & $63,50 \mathrm{~b}$ & $17,81 \mathrm{~b}$ \\
\hline 10,0 & 8,79 a & $26,85 c$ & $21,29 b$ & $58,04 \mathrm{c}$ & $20,67 \mathrm{c}$ \\
\hline \multicolumn{6}{|l|}{ Teste F } \\
\hline Inclinação (F1) & $1,63 \mathrm{~ns}$ & $1,44 \mathrm{~ns}$ & $1,32 \mathrm{~ns}$ & $1,64 \mathrm{~ns}$ & $1,84 \mathrm{~ns}$ \\
\hline Dosador (F2) & 12,16 ** & $1,45 \mathrm{~ns}$ & 19,78 ** & $7,57^{* *}$ & 4,88 * \\
\hline Velocidade (F3) & 12,57 ** & 19,07 ** & 11,58 ** & 42,44 ** & 66,78 ** \\
\hline $\mathrm{F} 1 \times \mathrm{F} 2$ & $0,95 \mathrm{~ns}$ & 1,42 ns & $2,60 \mathrm{~ns}$ & $3,13 \mathrm{~ns}$ & $1,60 \mathrm{~ns}$ \\
\hline $\mathrm{F} 1 \times \mathrm{F} 3$ & $0,83 \mathrm{~ns}$ & $1,17 \mathrm{~ns}$ & $1,54 \mathrm{~ns}$ & 2,98 * & 3,36 * \\
\hline $\mathrm{F} 2 \times \mathrm{F} 3$ & 2,91 * & $0,63 \mathrm{~ns}$ & $2,21 \mathrm{~ns}$ & $1,70 \mathrm{~ns}$ & $1,05 \mathrm{~ns}$ \\
\hline$F 1 \times F 2 \times F 3$ & $0,77 \mathrm{~ns}$ & $1,11 \mathrm{~ns}$ & $1,87 \mathrm{~ns}$ & $1,51 \mathrm{~ns}$ & $0,91 \mathrm{~ns}$ \\
\hline \multicolumn{6}{|l|}{ C. V. (\%) } \\
\hline Inclinação (F1) & 3,78 & 7,02 & 26,23 & 13,38 & 21,02 \\
\hline Dosador (F2) & 6,56 & 5,59 & 24,23 & 9,75 & 15,61 \\
\hline Velocidade (F3) & 4,15 & 4,39 & 12,38 & 5,86 & 11,47 \\
\hline Média geral & 8,92 & 25,84 & 19,47 & 62,93 & 17,60 \\
\hline
\end{tabular}

Em cada coluna, para cada fator, médias seguidas de mesmas letras minúsculas não diferem entre si, pelo teste de Tukey, a $5 \%$ de probabilidade.

ns = não-significativo $(P \geq 0,05) ;{ }^{*}$ significativo $(P \geq 0,05) ;{ }^{* *}$ significativo $(P \geq 0,01), C . V$. coeficiente de variação.

Para os espaçamentos falhos, o dosador cinza e o dosador verde não diferiram estatisticamente, apresentando valores médios de $17,11 \%$ e $16,75 \%$, respectivamente.

O diâmetro do disco utilizado quando este possui duas ou mais carreiras, foi determinado conforme descrito por Teixeira et al. (2009), como sendo o diâmetro médio das carreiras de orifícios dosadores. A velocidade periférica dos discos dos três dosadores não excedeu a referência citada (FAO apud Delafosse (1986) 0,29 $\mathrm{m} \mathrm{s}^{-1}$ ). A densidade de sementes de girassol por metro foi estabelecida de acordo com a população de 43.750,00 sementes ha-1, resultando em $3,5 \mathrm{sem} \mathrm{m}^{-1}$.

Para o teste F (Tabela 3 ), somente houve diferença estatística para a variável precisão quando analisado o fator inclinação (F1), a 1\% de probabilidade de erro. Já para os demais fatores, do- 
ALONÇO, A. dos S. et al. Distribuição longitudinal de sementes...

sador (F2) e velocidade (F3), todas as variáveis diferiram estatisticamente. Houve interação entre F1xF2 somente quando verificada a variável precisão, já para a interação $\mathrm{F} 1 \mathrm{xF} 3$ outras variáveis obti- veram diferença além da precisão, como o número de sementes por metro e espaçamentos falhos. Não houve interação entre os fatores $\mathrm{F} 2 \mathrm{xF} 3$, já para $\mathrm{F} 1 \mathrm{x}$ F2xF3 houve interação na variável precisão.

TABELA 3 - Resultados médios da análise de variância e do teste de médias para densidade de sementes, precisão e espaçamentos entre sementes de girassol.

\begin{tabular}{|c|c|c|c|c|c|}
\hline \multirow[b]{2}{*}{ Fatores } & \multicolumn{5}{|c|}{ Variáveis } \\
\hline & Sem $\mathrm{m}^{-1}$ & Precisão (\%) & Múltiplos (\%) & Aceitáveis (\%) & Falhos (\%) \\
\hline \multicolumn{6}{|l|}{ Inclinação (F1) } \\
\hline$-11^{\circ}$ & 3,86 & $22,36 b$ & 16,64 & 75,64 & 7,72 \\
\hline nivelado & 3,81 & $19,51 \mathrm{a}$ & 14,68 & 78,67 & 6,65 \\
\hline $11^{\circ}$ & 3,79 & $22,27 b$ & 17,01 & 73,52 & 9,47 \\
\hline \multicolumn{6}{|l|}{ Dosador (F2) } \\
\hline Amarelo & $3,39 a$ & $20,82 \mathrm{a}$ & $8,18 \mathrm{a}$ & $82,07 \mathrm{a}$ & $9,75 \mathrm{~b}$ \\
\hline Verde & $4,61 \mathrm{~b}$ & $20,86 a$ & $29,10 b$ & $67,23 \mathrm{~b}$ & $3,67 \mathrm{a}$ \\
\hline Cinza & $3,47 \mathrm{a}$ & $22,45 b$ & $11,05 a$ & $78,53 \mathrm{a}$ & $10,41 \mathrm{~b}$ \\
\hline \multicolumn{6}{|l|}{ Velocidade (F3) } \\
\hline 5,0 & $3,89 \mathrm{~b}$ & $19,90 \mathrm{a}$ & $14,40 \mathrm{a}$ & $80,47 a$ & $5,12 a$ \\
\hline 7,5 & $3,81 \mathrm{ab}$ & $21,10 \mathrm{~b}$ & $15,70 \mathrm{a}$ & $76,83 \mathrm{~b}$ & $7,47 \mathrm{~b}$ \\
\hline 10,0 & $3,76 \mathrm{a}$ & $23,13 \mathrm{c}$ & $18,22 b$ & $70,53 \mathrm{c}$ & $11,24 \mathrm{c}$ \\
\hline \multicolumn{6}{|l|}{ Teste F } \\
\hline Inclinação (F1) & $0,12 \mathrm{~ns}$ & $76,30^{* *}$ & $0,42 \mathrm{~ns}$ & $4,14 \mathrm{~ns}$ & $2,91 \mathrm{~ns}$ \\
\hline Dosador (F2) & 87,90 ** & 9,96 ** & 63,26 ** & 22,20 ** & 12,44 ** \\
\hline Velocidade (F3) & $5,07^{*}$ & $60,06 * *$ & 9,83 ** & 33,06 ** & $57,70 * *$ \\
\hline $\mathrm{F} 1 \times \mathrm{F} 2$ & $0,21 \mathrm{~ns}$ & 5,38 * & $0,07 \mathrm{~ns}$ & $0,18 \mathrm{~ns}$ & $0,16 \mathrm{~ns}$ \\
\hline$F 1 \times F 3$ & 3,26 * & $7,73^{* *}$ & $0,52 \mathrm{~ns}$ & $1,09 \mathrm{~ns}$ & 2,83 * \\
\hline $\mathrm{F} 2 \times \mathrm{F} 3$ & $2,19 \mathrm{~ns}$ & $0,88 \mathrm{~ns}$ & $1,29 \mathrm{~ns}$ & 1,42 ns & $1,53 \mathrm{~ns}$ \\
\hline$F 1 \times F 2 \times F 3$ & $1,71 \mathrm{~ns}$ & $5,43^{* *}$ & $0,47 \mathrm{~ns}$ & $0,83 \mathrm{~ns}$ & $2,09 \mathrm{~ns}$ \\
\hline \multicolumn{6}{|l|}{ C. V. (\%) } \\
\hline Inclinação (F1) & 13,86 & 4,51 & 62,06 & 8,68 & 54,43 \\
\hline Dosador (F2) & 9,87 & 7,16 & 45,99 & 11,26 & 68,87 \\
\hline Velocidade (F3) & 3,81 & 5,12 & 19,99 & 5,98 & 26,58 \\
\hline Média geral & 3,82 & 21,34 & 16,11 & 75,94 & 7,94 \\
\hline
\end{tabular}

Em cada coluna, para cada fator, médias seguidas de mesmas letras minúsculas não diferem entre si, pelo teste de Tukey, a $5 \%$ de probabilidade.

ns = não-significativo $(P \geq 0,05) ;{ }^{*}$ significativo $(P \geq 0,05) ;{ }^{* *}$ significativo $(P \geq 0,01), C . V$. coeficiente de variação. 
A média geral de densidade foi de 3,82 sem. $\mathrm{m}^{-1}, 9,14 \%$ acima do estabelecido no experimento, esta elevada densidade se dá pelo grande número de espaçamentos múltiplos do dosador verde, que apresentou média de 4,61 sem. $\mathrm{m}^{-1}$, $31,7 \%$ a mais do que o dimensionado.

A média de espaçamentos múltiplos de dosador verde ficou entre $29,10 \%$, muito próximos dos valores encontrados por Branquinho (2004) de $32,1 \%$. O dosador amarelo apresentou o menor valor de espaçamentos múltiplos $(8,18 \%)$, não diferindo do dosador cinza com 11,05\%. Com o aumento da velocidade de $7,5 \mathrm{~km} . \mathrm{h}^{-1}$ para a velocidade de $10 \mathrm{~km} \cdot \mathrm{h}^{-1}$ os resultados apresentaram valores significativamente diferentes. Os dosadores amarelo e cinza apresentaram uma diferença porcentual de $2,8 \%$ entre a densidade real e a regulada para as sementes de girassol, valores estes que concordam com os limites propostos por Siqueira e Casão Junior (2002) que citam valores até $\pm 10 \%$.

O índice de precisão mostrou que houve interação tripla entre os fatores, indicando que cada fator não age independentemente, situação encontrada apenas nesta variável. Os espaçamentos aceitáveis mostram que o dosador amarelo e o dosador cinza tiveram $82,07 \%$ e $78,53 \%$ respectivamente, diferenciando do dosador verde que obteve $67,23 \%$. O aumento da velocidade de semeadura influi significativamente no índice de espaçamentos aceitáveis, passando de $80,47 \%$ para $70,53 \%$ de média. O mesmo efeito se dá para os espaçamentos falhos, sendo 5,$12 ; 7,47$ e $11,24 \%$ de médias para as velocidades 5,0; 7,5 e 10,0 km $\mathrm{h}^{-1}$, respectivamente.

De acordo com a classificação sugerida por Tourino e Klingensteiner (1983), os dosadores de cor amarela e cinza apresentaram um bom desempenho e o dosador verde teve desempenho regular, no que se refere aos espaçamentos aceitáveis. Entretanto, nenhum dos dosadores atingiu o limite proposto por Coelho (1996), em que dosadores pneumáticos devem proporcionar a uniformidade de espaçamentos entre sementes, dentro da linha, acima de $90 \%$.

\section{CONCLUSÃO}

Para a cultura do algodão, o dosador amarelo foi o que apresentou maior eficiência, de acordo com as análises das variáveis estudadas. O aumento da velocidade influiu significativamente nos espaçamentos aceitáveis e falhos, e na precisão.

Para a cultura do girassol, o dosador amarelo também apresentou maior eficiência, pela análise das variáveis estudadas. O aumento da velocidade de semeadura influiu significativamente nos resultados médios de espaçamentos aceitáveis e falhos, além da precisão. Também, as inclinações positivas e negativas alteraram os resultados em relação à média (nivelada), diferindo estatisticamente na variável precisão.

Com isso, o dosador amarelo mostrou meIhores resultados para as culturas do algodão e girassol, salvo as condições detalhadas em cada capítulo.

\section{REFERÊNCIAS}

1. ABNT - Associação Brasileira de Normas Técnicas. Projeto de norma 04: 015.06 - 004: Semeadora de precisão ensaio de laboratório - método de ensaio. São Paulo, 1994. 26 p.

2. ALONÇO, A. dos S.; SILVEIRA, H., A., T. da; ZOTTIS, J.; BEDIN, P., R.; DIAS, V., de O. Projeto de uma bancada para ensaios de dosadores pneumáticos de sementes: fase informacional e conceitual. In: IX Congreso Latinoamericano y del Caribe de Ingeniería Agrícola - CLIA 2010, XXXIX Congresso Brasileiro de Engenharia Agrícola - CONBEA 2010, Anais... Vitória: Sociedade Brasileira de Engenharia Agrícola, 2010. 1 CD - ROM.

3. BALASTREIRE, L. A. Máquinas Agrícolas. 1 ed. São Paulo: Manole, 1987. 310 p.

4. BRANQUINHO, Klinger B. et al. Desempenho de uma semeadora-adubadora direta, em função da velocidade de deslocamento e do tipo de manejo da biomassa da cultura de cobertura do solo. Eng. Agríc. [online]. 2004, vol.24, n.2, pp. 374 -380. ISSN 0100-6916. doi: 10.1590/S0100-69162004000200016.

5. COELHO, J. L. D. Ensaio \& Certificação das máquinas para a semeadura. In: Luiz Geraldo Mialhe. Máquinas Agrícolas: ensaios \& certificação. Piracicaba: FEALQ, 1996. p. $551-570$.

6. DELAFOSSE, R. M. Máquinas sembradoras de grano gruesso. Santiago: Oficina Regional de La FAO para America Latina y el Caribe, 1986, $48 \mathrm{p}$.

7. FEY, E.; WEIRICH, P. H.; SANTOS, S. R. Efeito da velocidade tangencial do mecanismo dosador, tipo disco alveolado horizontal na distribuição de sementes de feijão. In: CONGRESSO BRASILEIRO DE ENGENHARIA AGRÍCOLA, 29., 2000, Fortaleza. Anais... Fortaleza: Sociedade Brasileira de Engenharia Agrícola, 2000. 1 CD-ROM.

8. FURLANI, C. E. A.; LOPES, A.; ABRAHÃO, F. Z.; LEITE, M. A. S. Características da cultura do milho (Zea mays L.) em função do tipo de preparo do solo e da velocidade de semeadura. Engenharia Agrícola, Jaboticabal, v. 19, n. 2, p. 177 186, 1999.

9. GARCIA, Luiz C. et al. Influência da velocidade de deslocamento na semeadura do milho. Eng. Agríc. [online]. 2006, vol.26, n.2, pp. 520-527. ISSN 0100-6916. doi: 10.1590/S0100-69162006000200021.

10.INTERNATIONAL ORGANIZATION FOR STANDARDIZATION. ISO: 7256/1: Sowing equipment - methods of test: part 1. Single seeddrills (precisiondrills). Geneva, 1982. $16 \mathrm{p}$.

11.JASPER, R.; JUSTINO, A; MORGADO, C. B.; DYCK, R.; GARCIA, L. C. Comparação de bancadas simuladoras do processo de semeadura em milho. Engenharia Agrícola, Jaboticabal, v. 29, n. 4, p. 623 - 629, out./dez. 2009.

12.KACHMAN, S. D.; SMITH, J. A. Alternative measures of accuracy in plant spacing for planters using single seed metering. Transactions of the ASAE, St. Joseph, v. 38, n. 2, p. 379-387, mar./abr. 1995.

13.KURACHI, S. A. H.; COSTA, J. A. S.; BERNARDI, J. A.; COELHO, J. L. D.; SILVEIRA, G. M. Avaliação tecnológica de semeadoras e/ou adubadoras: tratamento de dados de ensaios e regularidade de distribuição longitudinal de sementes. 
ALONÇO, A. dos S. et al. Distribuição longitudinal de sementes...

Bragantia, Campinas, v. 48, n. 2, p. $249-262,1989$.

14.MACHADO, A. L. T.; REIS, A. V.; MORAES, M. B.; ALONÇO, A. S. Máquinas para Semeadura e Adubação In: Máquinas para preparo do solo, semeadura, adubação e tratamentos culturais.2. ed. Pelotas: Ed. Universitária UFPEL, 2005. p. $101-190$.

15.MAHL. D. et al. Demanda energética e eficiência da distribuição de sementes milho sob variação de velocidade e condição de solo. EngenhariaAgrícola,Jaboticabal, v. 24, n. 1, p. 150 - 157, jan./abr. 2004.

16.MURRAY, J. R.; TULLBERG, J. N.; BASNET, B.B. Planters and their Components: types, attributes, functional requirements, classification and description. ACIAR Monograph $n^{\circ} 121$. University of the Queensland, Australia, 2006. $178 p$.

17.ROMANO, L. N. Modelo de Referência para o Processo de Desenvolvimento de Máquinas Agrícolas. 266 p. Tese (Doutorado em Engenharia Mecânica) - Universidade Federal de Santa Catarina, Florianópolis, 2003.

18.SANTOS, A. P.; TOURINO, M. C. C.; VOLPATO, C. E. S. Qualidade de semeadura na implantação da cultura do milho por três semeadoras-adubadoras de plantio direto. Ciência e Agrotecnologia (UFLA), v. 32, p. 1601-1608, 2008.

19.SILVA, J. G; KLUTHCOUSKI, J; SILVEIRA, P. M. Desempenho de uma semeadora-adubadora no estabelecimento e na produtividade da cultura do milho sob plantio direto. Scientia Agrícola, v. 57 n. 1. Piracicaba jan./mar. 2000.

20.SILVEIRA, H., A., T. da; ALONÇO, A. dos S.; ZOTTIS, J.; DIAS, V. de O.; BAUMHARDT, U. B.; Projeto e desenvolvimento de uma bancada para ensaios de dosadores de sementes pneumático: fase preliminar e detalhada. In: IX Congreso Latinoamericano y del Caribe de Ingeniería Agrícola - CLIA 2010, XXXIX Congresso Brasileiro de Engenharia Agrícola - CONBEA 2010, Anais... Vitória: Sociedade Brasileira de Engenharia Agrícola, 2010. 1 CD - ROM.

21.SIQUEIRA, R.; CASÃO JUNIOR, R. Dinâmica de semeadoras adubadoras diretas em entre rios do oeste - PR (resultados de avaliação). Londrina - PR: IAPAR, 2002. (Avulso).

22.TEIXEIRA, S. S.; REIS, A. V. dos; MACHADO, A. L. T.; BISOGNIN, A.; SILVEIRA, H. A. T. Distribuição longitudinal de sementes de milho com dosador de disco horizontal operando com uma ou duas saídas de sementes. Ciência Rural, Santa Maria, v. 39, n. 8, p. $2417-2421$, nov., 2009.

23.TESOURO, M.O.; ROMITO, A.; COLOMBO, C.; POLLACINO, J.C.; PINCU, M.S. Efecto de launiformidad del tamaño dela semilla de girasol (Helianthusannuus $L$.) sobre la precisón del sistema dosificador. In: CONGRESO AMERICANO DE EDUCACIÓN EN INGENÍERIA AGRÍCOLA, 2., 2000, Buenos Aires. Anales... Buenos Aires: Universidad de Buenos Aires, 2000. p.158-164.

24.TOURINO, M. C.; KLINGENSTEINER, P. Ensaios e avaliação de semeadoras adubadoras. In: CONGRESSO BRASILEIRO DE ENGENHARIA AGRÍCOLA, 13, 1983, Rio de Janeiro - RJ. Anais. Rio de Janeiro: UFRRJ, 1983. v. 2, p. 103 - 116.

25.VIEIRA, J. A. Plantio direto na região de primavera do leste, Mato grosso. 75 f. Dissertação (Mestrado em Fitotecnia) Universidade Federal de Viçosa. 2002.

Recebido em 27/092012 Aceito em 31/03/2015 